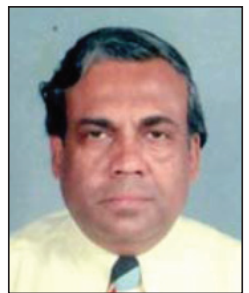

JOURNAL OF MINES, METALS \& FUELS www.jmmf.info

CHOICE ${ }^{\mathrm{TM}}$

Shyamal Kumar Bag

Managing Director, Merchentus India

Exim International LLP and Technical

Support at Dos Santos International

\title{
High angle conveying in opencast mines can be green, efficient, economic and flexible
}

Sandwich High Angle Conveyor (HAC) is a special type of conveyor system, where the material is hugged between the top and bottom conveyor belts and carried at any steep angle up to 90 degrees. The system is able to elevate material high in a limited horizontal space. This system can be imagined as an elevator in a high-rise, where one can easily reach the top floor- in short time and avoiding the staircase. Since DSI Snake HAC angle covers the material from both top and bottom, hence, there is no chance of dust generation during operation. In opencast mine, transport cost is around $60 \%$ of total mining cost. Hence, the adoption of the HAC system especially in deeper opencast mines shall save huge mining costs. HAC locations are generally along the sidewall, which may have to be shifted if required with the progress of mine. Haul road is generally zigzag to maintain permissible gradient for movement of dumpers. In-pit conveyor also has to follow haul road. As such, in-pit conveyor system may have to split. In the above example, the in-pit conveyor has been split into four segments and shall require at least three number of transfer points/ transfer houses. On the other hand HAC shall be generally one unit or may be two systems to cater to multi-seams. The author compared three choices: (a) HAC, in-pit crusher (IPC) at pit bottom, and short dumper transport from the coal face to IPC/ HAC, (b) short dumper travel from the coal face to IPC at pit bottom, in-pit conveyor from the pit bottom to surface following the haul road, (c) dumper transport from the pit bottom to the surface crushing plant. The author has developed a programme based on various statistical data and also calculation norms for HEMM by CIL/CMPDI and hence, can be relied upon. Comparisons are done for three cases based on annual production of $10 \mathrm{Mtpa}$ and with three mine depths i.e., $100 \mathrm{~m}, 150 \mathrm{~m}$, and $200 \mathrm{~m}$. From the results, it can be easily concluded that with an increase of mine depth, the $\mathrm{HAC}$ is more and more economical over the other two alternatives, and due to huge savings over dumper transport system, the payback period for investment against DSI HAC shall be only one year. It may not be out of place to mention here that with the increase of annual production of more than 10 Mtpa the savings for DSI HAC will be more significant. Please see the results in the figure (Annexure).

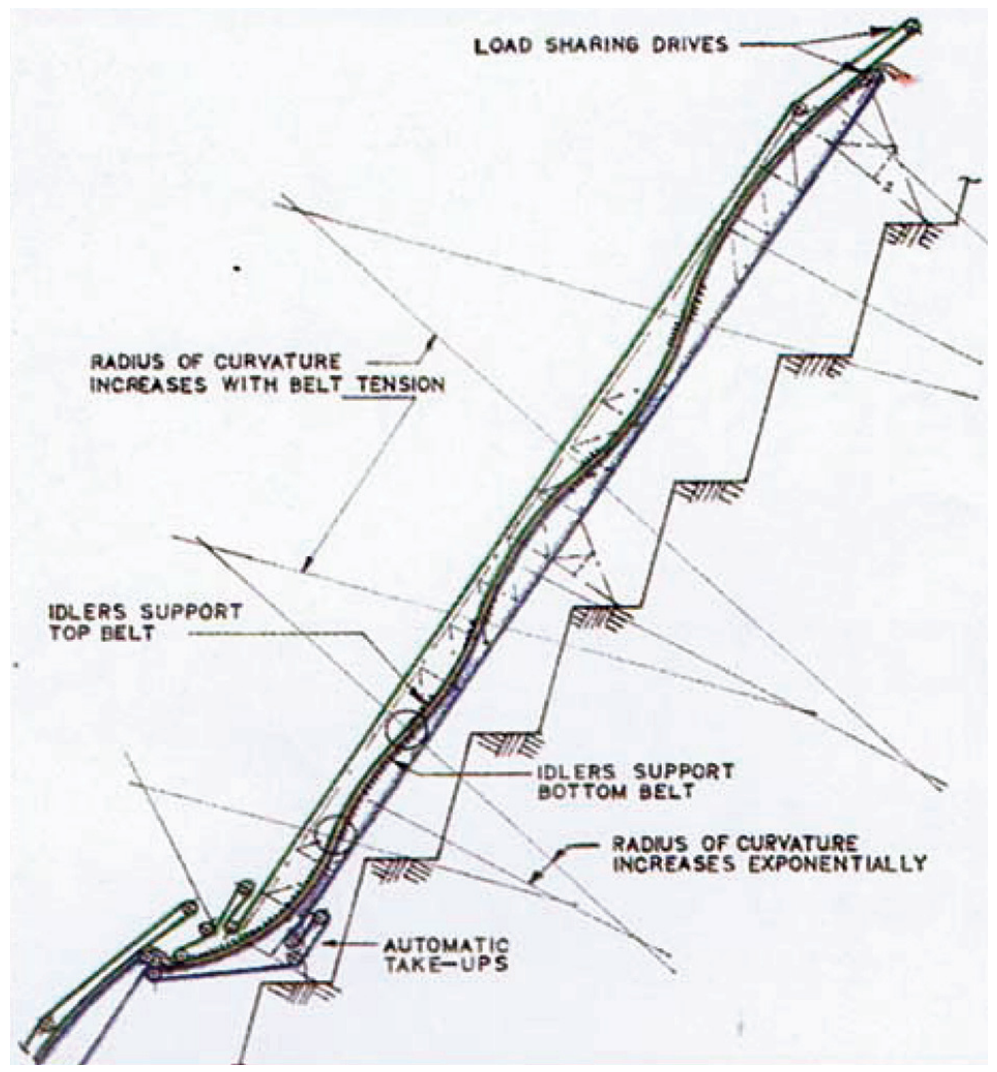


SUMMARISED STATEMENT OF INPUTS

COMPARISON OF TRANSPORT COST BY DSI SNAKE HIGH ANGLE CONVEYOR, IPCC AND DUMPER TRANSPORT SYSTEM FROM PIT BOTTOM IN OPENCAST MINE

SUMMARISED COMPARATIVE STATEMENT FOR SYSTEM - I,II \& III

System - I: In-pit crusher, DSI Snake HAC from pit bottom to surface and dumper shuttle at coal face

System - II: In-pit crusher, conveyor from in-pit crusher to surface chp and dumper shuttle at coal face to in-pit crusher

System - III: Dumper transport from coal face to surface and crushing of coal at surface

IN-PUT DATA TABLE

1. Total annual production (MTe)

2. Capacity of the system (TPH)

3. Annual operating hours (Hrs)

4. Lead distance of dumper (one way) from coal face

to surface chp for System II (kM)

5. Lead distance of dumper (one way)

from coal face to in-pit crushing station for System I (kM)

6.Depth of mine

7. Dumper capacity (Te)

7. Length of IPC conveyor (meter)

8.Length of DSI Snake HAC (meter)

\section{coal face}

\begin{tabular}{|l|l|l|}
\hline$x$ \\
\hline \\
\hline \\
\hline
\end{tabular}

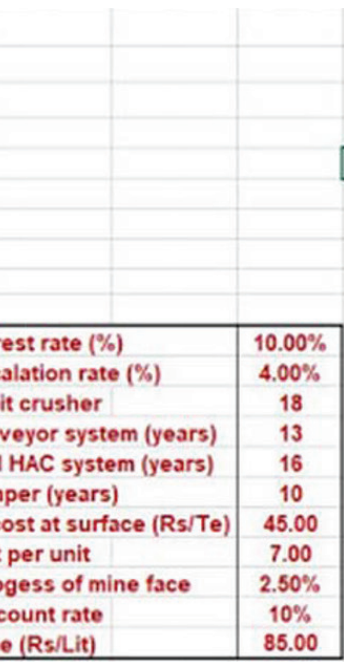
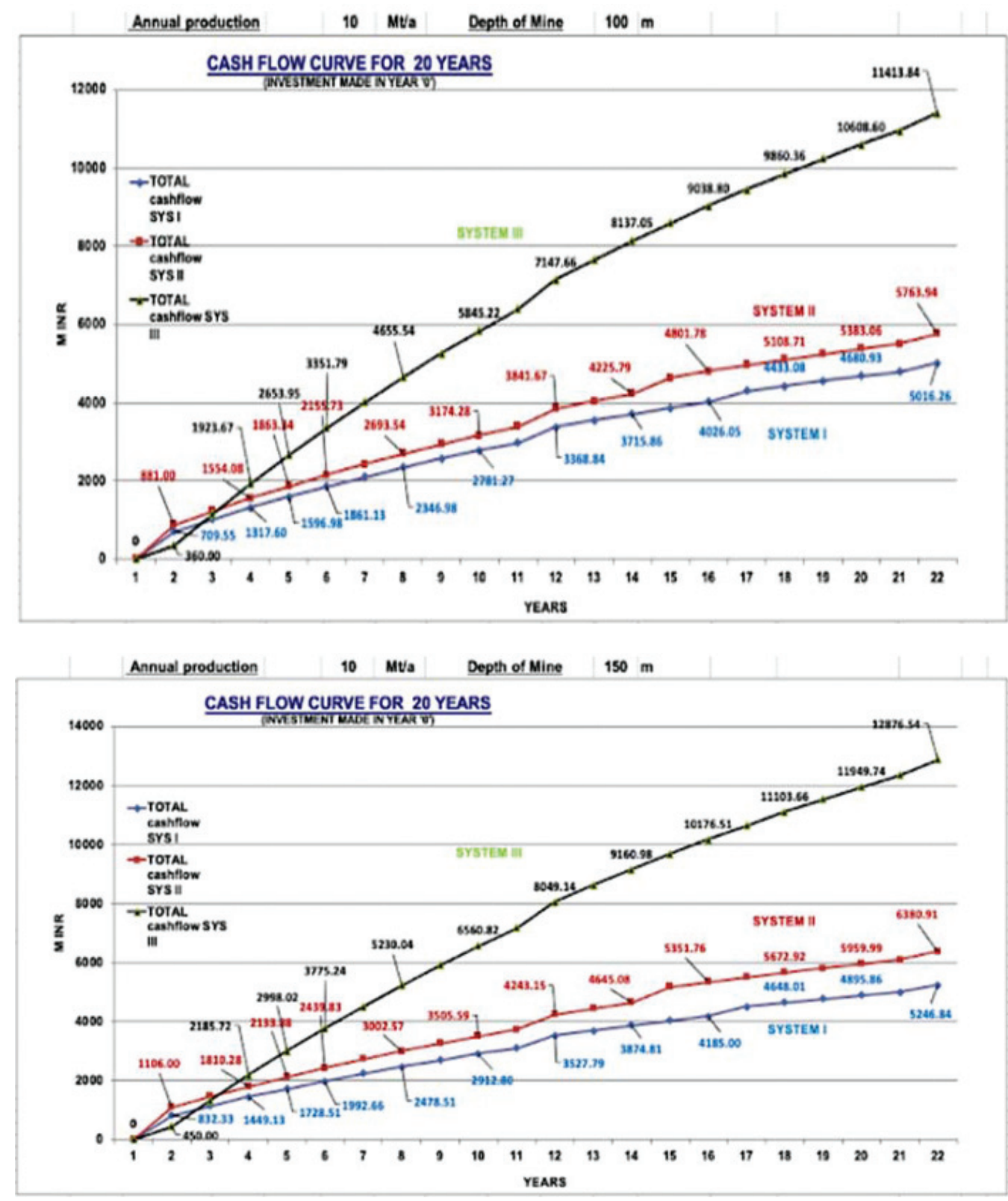